\title{
İŞE BAĞLI DUYGUSAL TÜKENMISSLIK: BİR ÖLÇEK UYARLAMA ÇALIŞMASI
}

\section{Ahmet GÜNAY ${ }^{1}$}

\begin{tabular}{|c|c|}
\hline Makale I & Bilgisi \\
\hline $\begin{array}{l}\text { Araştırma } n \\
\text { DOI: } 10.35\end{array}$ & $\begin{array}{l}\text { nakalesi } \\
\text { 379/cusosbil.828921 }\end{array}$ \\
\hline Makale Gec & cmissi: \\
\hline Geliş & 20.11 .2020 \\
\hline Düzeltme & 23.02 .2021 \\
\hline Kabul & 16.03.2021 \\
\hline Anahtar Ke & limeler: \\
\hline Tükenmişlih & \\
\hline Duygusal T & ükenmişlik, \\
\hline Işse Bağll D & uygusal Tükenmişlik. \\
\hline
\end{tabular}

Jel Sinıflandırma Kodları: M10, M50

\section{ÖZ}

Bu araștırmanın amacı "İse Bağlı Duygusal Tükenmișlik Ölçeği”nin (Job-Related Emotional Exhaustion Scale) Türkçe uyarlamasını yapmak, geçerlilik ve güvenilirlik analizlerini gerçekleștirmektir. Araștırmanın örneklemini Isparta ili hizmet sektöründe çalışmakta olan çalışanlar oluşturmaktadır. Bu kapsamda 411 katılımcıya ulaşılmıştır. Gerçekleştirilen açımlayıcı faktör analizi neticesinde toplam varyansın \%68'ini açıklayan 6 ifadeli ve tek boyutlu bir yapıya ulaşılmıștır. Gerçekleștirilen doğrulayıcı faktör analizi neticesinde ölçme aracının iyi uyum seviyesine sahip olduğu tespit edilmiștir. Ölçeğe dair gerçekleștirilen güvenilirlik analizi neticesinde ise Cronbach alfa iç tutarlılık katsayısı .903 olarak bulunmuş ayrıca iki yarı güvenilirliğe ait değerlerden madde korelasyonu .839 , Spearman-Brown katsayısı ise .913 olarak bulunmuştur. $\mathrm{Bu}$ bilgiler 1şı̆̆ında "İșe Bağlı Duygusal Tükenmişlik Ölçeği”nin Türk kültürüne uygun, geçerli ve güvenilir bir ölçme aracı olduğunu ifade etmek mümkündür.

\section{JOB-RELATED EMOTIONAL EXHAUSTION: A SCALE ADAPTATION} STUDY

\begin{tabular}{l} 
Article Info \\
\hline Research Article \\
DOI: $10.35379 /$ cusosbil.828921 \\
\hline Article History: \\
Received 20.11.2020 \\
Revised 23.02.2021 \\
Accepted 16.03 .2021 \\
\hline Keywords: \\
Burnout, \\
Emotional Exhaustion, \\
Work-related-Emotional \\
Exhaustion \\
JEL Classification Codes: M10, \\
M50 \\
\hline
\end{tabular}

\begin{abstract}
The aim of this study is to adapt the "Job-Related Emotional Exhaustion Scale" to Turkish and to perform validity and reliability analysis. The sample of the study consists of employees in the service sector of Isparta. In this context, 411 participants were reached. As a result of the exploratory factor analysis, a one-dimensional structure with 6 expressions that explains $68 \%$ of the total variance emerged. As a result of the confirmatory factor analysis carried out, it was determined that the measuring tool has a good level of adaptation. With this reliability analysis of the scale, the Cronbach alpha internal consistency coefficient was found to be .903 . The item correlation among the two-half reliability values was found to be .839 and the Spearman-Brown coefficient as .913. Therefore, it is possible to state that the "Job-Related Emotional Exhaustion" is a valid and reliable measurement tool suitable for Turkish culture.
\end{abstract}

\footnotetext{
${ }^{1}$ Dr. Öğr. Üyesi, Süleyman Demirel Üniversitesi, İletişim Fakültesi, ahmetgunay@ @sdu.edu.tr, ORCID: 0000-0002-7826-3682 Alıntılamak için/Cite as: Günay, A., İşe Bağlı Duygusal Tükenmişlik: Bir Ölçek Uyarlama Çalışması, Çukurova Üniversitesi Sosyal Bilimler Enstitüsü Dergisi, 30 (1), 142-149.
} 
Çukurova Üniversitesi Sosyal Bilimler Enstitüsü Dergisi, Cilt 30, Sayı 1, 2021, Sayfa 142-149

\section{GíRiș}

İlk olarak Bradley (1969) tarafından ortaya atılan tükenmişlik kavramı özellikle sağlık hizmetleri, kolluk kuvvetleri ve sosyal hizmet gibi insan odaklı mesleklerde çalışanları ilgilendiren psikolojik bir gerginlik türü olarak ifade edilmiştir. Zamanla gerçekleştirilen çalışmalar hemen hemen tüm meslek gruplarında farklı şiddetlerde de olsa, iş gereksinimleri ve çalışanların algılanan yeteneklerinin uyuşmadığg her türlü örgütte tükenmişliğin mevcudiyetini ortaya koymuştur (Brown, 2012).

Sözlük anlamı gücünü yitirmiş olma ve çaba göstermeme durumu olarak tanımlanan tükenmişlik (sozluk.gov.tr), duygusal tükenmişlik, duyarsılaşma (diğerlerinden uzaklaşma) ve düşük kişisel performansla karakterize edilen bir kavramdır (Maslach ve Jackson, 1984). Bireyin içsel enerji kaynaklarının giderek azalmasını ifade eden bu kavram (Shirom ve Cooper, 1989), bireyin kendisi ya da toplum tarafindan bireye dayatılan aşırı taleplerin neden olduğu ve kişinin motivasyonunu, tutumlarını ve nihayet davranışlarını etkileyen bir unsurdur (Freudenberger ve North, 1986).

İş yerindeki kronikleşmiş olan duygusal ve kişilerarası stres faktörlerine bağlı olarak uzun sürede ve yavaş bir şekilde gelişen duygusal tükenmişlik (Maslach ve ark., 2001), iş performansını etkileyebilirken aynı zamanda personel değişimini hızlandırarak örgütün sahip olduğu insan sermayesini de zayıflatabilir (Burke ve Richardsen, 1993). Buradan hareketle duygusal tükenmişliğin yalnızca bireyleri ilgilendiren bir unsur olmadığını, örgütleri de en az çalışanlar kadar ilgilendirdiğini söylemek mümkündür (Schulz ve ark., 1996).

Duygusal tükenmişliğe yönelik gerçekleştirilen mevcut araştırmalar pek çok farklı neden ortaya koysa da bu nedenlerin temelinde genellikle işle ilgili faktörler, örgütsel faktörler ve kişisel faktörler olmak üzere üç temel kategori ortaya çıkmıştır (Cooper ve ark., 2001). İşle ilgili faktörler; çalışma saati, çalışma düzeni, işin niteliği, rol belirsizliği, fiziki konfor gibi işin getirdiği fiziksel ve ruhsal zorlukları barındırmaktadır (Wittmer ve Martin, 2010). Örgütsel faktörler; çalışma ortamı, dayanışma, adalet, algılanan sosyal destek, iş firsatları, kariyer engelleri gibi örgütün genel doğasını ve iklimini yansıtan özellikleri barındırmaktadır (Lee ve Ashforth, 1996). Son olarak kişisel faktörler ise bireyin kişiliği, hedefleri, örgüte olan uyumu, arkadaşları, ailesi, demografik özellikleri gibi doğrudan kişiyle ilgili olan özellikleri kapsamaktadır (Ghorpade ve ark., 2007). İşle ilgili, örgütsel ya da kişisel faktörlerin tamamı hem doğrudan hem de dolaylı olarak duygusal tükenmişliği etkileyebilmektedir (Schaible ve Gecas, 2010).

Maslach (1978) tarafından genellikle düşük iş tatmini ve performanstaki kötüleşmeyle işaretlenen duygusal tükenmişlik; yorgunluk, işten kopma, aidiyet hissini kaybetme, yönelim bozuklukları, somatik şikâyetler, depresyon ve bazen de fiziksel problemler şeklinde kendini göstermektedir (Reiner ve Hartshorne, 1982). Her ne kadar Maslach (2001), tükenmişliğin üç yordayıcısının da eşit nitelikte olduğunu ve tükenmişliği anlayabilmek için adı geçen değişkenlerin eksiksiz incelenmesi gerektiğini ifade etse de özellikle son yıllarda yapılan çalışmaların duygusal tükenmişlik üzerine yoğunlaştığı, belirtilen kişisel başarı ile duyarsızlaşmanın duygusal tükenmişlik kapsamında incelendiği ve hatta tükenmişlik denince akla yalnızca duygusal boyutun geldiği ifade edilebilir (Shirom, ve Cooper, 1989).

Türkçe yazın incelendiği zaman duygusal tükenmişlikle ilgili ortaya koyulan ölçüm araçlarının genellikle meslek gruplarına dair özelleştiği anlaşılmaktadır. Tümkaya (2000) tarafından Akademik Tükenmişlik Ölçeği, Aypay (2011) İlköğretim 2. Kademe Öğrencileri İçin Okul Tükenmişliği Ölçeği, Kelecek ve arkadaşları (2016) tarafından uyarlanan Sporcu Tükenmişlik Ölçeği Türkçe Uyarlaması, Secer ve Halmatoc (2013) tarafindan uyarlanan Okul Tükenmişlik Ölçeğinin Türk Kültürüne Uyarlanması mevzu bahis ölçüm araçlarından bazılarıdır. Ayrıca Türkçe yazında Tümkaya ve arkadaşları (2009) tarafından uyarlanan Tükenmişlik Ölçeği Kısa Versiyonunun Türkçe'ye Uyarlama Geçerlilik ve Güvenilirlik Çalışması bu çalışmaya benzer olarak dikkat çekmektedir. Bu çalışma ise 6 ifadeden oluşması ve tek bir meslek grubuna ait olmaması nedenleriyle diğerlerinden ayrışmaktadır.

Duygusal tükenmişlikle ilgili gerçekleştirilen çalışmalar incelendiği zaman Uluslararası ve Türkçe yazında kişilik (Edwards ve ark, 1990), iş stresi (Cherniss ve Cherniss, 1980; Cox ve ark., 1993), örgütsel bağlılık (Omdahl ve O’Donnell, 1999; Brown ve Roloff, 2011; Yeniçeri ve ark,2009), iş yaşam dengesi (Shanafelt ve ark., 2012), iş-aile çatışması (Burke ve Greenglass, 2001; Wang ve ark., 2011), performans (Halbesleben ve Brown, 2007), duygusal zekâ (Moon ve Hur, 2011), örgütsel vatandaşlık (Cropanzano ve ark., 2003), duyarsızlaşma (West ve ark., 2009), liderlik (Stordeur ve Vandenberghe, 2001), sinizm (Gkorezis ve ark., 2015), örgütsel adalet (Cole ve ark., 2010), işten ayrılma niyeti (Houkes ve ark., 2003), motivasyon (Halbesleben ve Bowler, 2007; Skaalvik ve Skaalvik, 2016), psikolojik iyi oluş (Jeon ve ark., 2016), depresyon (Schermuly ve Meyer, 2016), kariyer (Bozionelos, 2006), iyimserlik (Mäkikangas ve Kinnunen, 2003), özgüven (Papathanasiou ve ark., 2014) ve demografik değişkenlerle (Garrosa ve ark., 2008) anlamlı ilişkiler tespit edilmiştir. 


\section{ARAȘTIRMANIN METODOLOJISİ}

Süleyman Demirel Üniversitesi Etik Kurulu'ndan alınan 11.11.2020 Tarih 87432956-050.99-E sayıll, 30.06.2020 tarihli Etik Kurul Onayı ile yürütülen bu çalışmada kullanılan orijinal ölçeğin Türkçe uyarlaması, geçerlilik ve güvenilirlik analizine dair yapılan işlemler bu başılı altında sırası ile verilecektir.

\section{Çalış̧ma Grubu}

$\mathrm{Bu}$ çalışmanın örneklemini Isparta ili hizmet sektöründe çalışanlar oluşturmaktadır. Hizmet sektörü çalışanları, sağlık sektörü çalışanları ile birlikte duygusal tükenmişliğin yoğun olarak gözlenebildiği sektörlerden olduğu gerekçesi ile tercih edilmiştir (Salanova ve Llorens, 2008). Çalışma kapsamında kolayda örnekleme yoluyla hizmet sektöründe çalışmakta olan 411 kişiye ulaşılmış ve bunlardan gelişi güzel ya da eksik dolduran 25 anket çalışma dışında bırakılmıştır. 2020 Yılında Isparta ili hizmet sektöründe çalışan kişi sayısına dair yeterli veri olmamakla birlikte ulaşılan kişi sayısı itibariyle $(n=385)$ ölçekteki ifade sayısı da göz önünde bulundurularak yeter sayıya ulaşıldığına kanaat getirilmiștir. Nitekim Kline (1994) ölçekte bulunan ifade sayısının mümkünse 10 katı sayıya ulaşmasının evrenin temsili açısından yeterli olduğunu belirtmiştir. Katılımcıların 220'si (\%57,1) kadın, 165'i (\%42,8) erkeklerden oluşmaktadır.

\section{Orijinal Ölçme Aracı}

Maslach (1986) tarafından geliştirilen Tükenmişlik Ölçeği (Burnout Scale) 3 boyut ve 22 ifadeden oluşmaktadır. Ölçekte 9 ifadeden oluşan duygusal tükenmişlik, 8 ifadeden oluşan kişisel başarı ve 5 ifadeden oluşan duyarsızlaşma boyutları bulunmaktadır. Wharton (1993), Maslach tarafindan geliştirilen bu ölçekten esinlenerek 6 ifade ve tek boyutlu İşe Bağlı Duygusal Tükenmişlik Ölçeğini (Job-Related Emotional Exhaustion Scale) geliştirmiş̧ir. Ölçekteki ifadelerin 5 tanesi Maslach tarafından geliştirilen Tükenmişlik Ölçeğinin duygusal tükenmişlik boyutu ile birebir aynı olup yalnızca 1 ifadede değişikliğe gidilmiştir. İşe Bağlı Duygusal Tükenmişlik Ölçeğinin alfa katsayısı .87 olup, ölçekteki ifadeler $5^{\prime}$ li likert tipi olarak geliştirilmiş ve $0=$ iş yerinde asla bu şekilde hissetmiyorum, 4 = her gün bu şekilde hissediyorum olacak şekilde dizayn edilmiştir.

\section{İşlem}

Orijinal ölçek olan İşe Bağlı Duygusal Tükenmişlik Ölçeğindeki ifadeler Türkçeye çevrilmiş ve ardından çevirmeleri için 5 öğretim üyesine gönderilmiştir. Öğretim üyeleri ve araştırmacı tarafından yapılan çevirilerin büyük oranda benzer olması üzerine Türkçe ifadeler yeniden kaynak dile çevrilmesi maksadıyla Süleyman Demirel Üniversitesi Yabancı Diller Yüksekokulu'nda görev yapmakta olan 3 öğretim elemanına gönderilmiştir. Dil uzmanlarının yaptığı çeviriler ile orijinal ölçekteki ifadelerin hemen hemen aynı olduğuna kanaat getirilerek ölçeğin geçerlilik ve güvenilirlik analizine geçilmiştir. Ölçeğin yapı geçerliliğinin sınanması maksadıyla hem açımlayıcı faktör analizi (AFA) hem de doğrulayıcı faktör analizi (DFA) yapılmıştır. Ayrıca İșe Bağlı Duygusal Tükenmişlik Ölçeğinin güvenilirliğinin sınanması amacıyla iç-tutarlılık ve madde analizi için düzeltilmiş madde toplam korelasyonları incelenmiştir. Belirtilen işlemleri gerçekleştirmek üzere SPSS 26 ve AMOS paket programlarından faydalanılmıştır.

\section{BULGULAR}

İşe Bağlı Duygusal Tükenmişlik Ölçeğinin Türkçe uyarlaması için öncelikle yapı geçerliliğine, sonrasında ise güvenilirliğine bakılmıştır. Yapılan işlemler ve detayları aşağıda sırası ile verilmiştir.

\section{Yapı Geçerliliği}

İşe Bağlı Tükenmişlik Ölçeğinin yapı geçerliliğinin sınanması maksadıyla ilk olarak AFA uygulanmıştır. Gerçekleştirilen AFA neticesinde ölçeğin orijinaline uygun şekilde tek boyutlu bir yapıda olduğu görülmüştür. Tablo1'de AFA'ya dair detaylar yer almaktadır.

\begin{tabular}{|c|c|c|c|c|}
\hline $\begin{array}{c}\text { Madde } \\
\text { No }\end{array}$ & Madde & Ortalama & $\begin{array}{c}\text { Standart } \\
\text { Sapma }\end{array}$ & $\begin{array}{c}\text { Faktör } \\
\text { Yükü } \\
\end{array}$ \\
\hline 1 & İşimden dolayı duygusal olarak tükenmiş hissediyorum & 2.79 & 1.215 & .910 \\
\hline 2 & İş gününün sonunda kendimi bitkin hissediyorum & 3.30 & 1.186 & .869 \\
\hline 3 & $\begin{array}{l}\text { Sabah kalkmaktan ve iş yerinde yeni bir günle yüzleşmek zorunda olmaktan } \\
\text { yıldım }\end{array}$ & 2.44 & 1.341 & .858 \\
\hline 4 & İşimden dolayı psikolojik olarak yıpranmış hissediyorum & 2.64 & 1.391 & .843 \\
\hline 5 & İşimden dolayı hayal kırıklığına uğramış hissediyorum & 2.30 & 1.382 & .840 \\
\hline 6 & İşimde çok çalıştığımı hissediyorum & 3.45 & 1.347 & 614 \\
\hline
\end{tabular}


Tablo 1'den de anlaşılabileceği gibi İşe Bağlı Duygusal Tükenmişlik Ölçeğine ait ifadelerin faktör yükleri .910 ile .614 arasında değişen değerler almaktadır. İfadelere ait faktör yüklerinin .50’nin üzerinde olması yeterli görüldüğü için (Nunnally, 1978) maddelerin hiçbiri analiz dışında bırakılmamıştır. Gerçekleştirilen AFA neticesinde tek boyutlu bir yapı olarak karşımıza çıkan ölçeğin açıklanan toplam varyansı 68.533, özdeğer ise 4.112 olarak tespit edilmiştir.

İşe Bağlı Duygusal Tükenmişlik Ölçeğine uygulanan AFA'dan elde edilen sonuçlardan hareketle DFA gerçekleştirilmiş olup ölçeğe dair uyum iyiliği değerleri Tablo 2'de verilmiştir.

\begin{tabular}{|c|c|c|c|c|c|c|c|c|}
\hline & $\chi^{2 /(d f)}$ & RMSEA & NFI & GFI & AGFI & TLI & CFI & RFI \\
\hline $\begin{array}{l}\text { İşe Bağlı } \\
\text { Duygusal } \\
\text { Tükenmişlik } \\
\text { Ölçeği }\end{array}$ & 2.982 & .078 & .982 & .977 & .939 & .975 & .987 & .966 \\
\hline
\end{tabular}

Tablo 2'de görüleceği üzere gerçekleştirilen DFA neticesinde ölçeğe ait uyum iyiliği değerlerinin iyi uyum seviyesinde (Forza ve Filipini, 1998) olduğu anlaşılmaktadır. 6 ifade ve tek boyuttan oluşan İşe Bağlı Duygusal Tükenmişlik Ölçeğinin yol analizi Şekil 1'de verilmiştir.

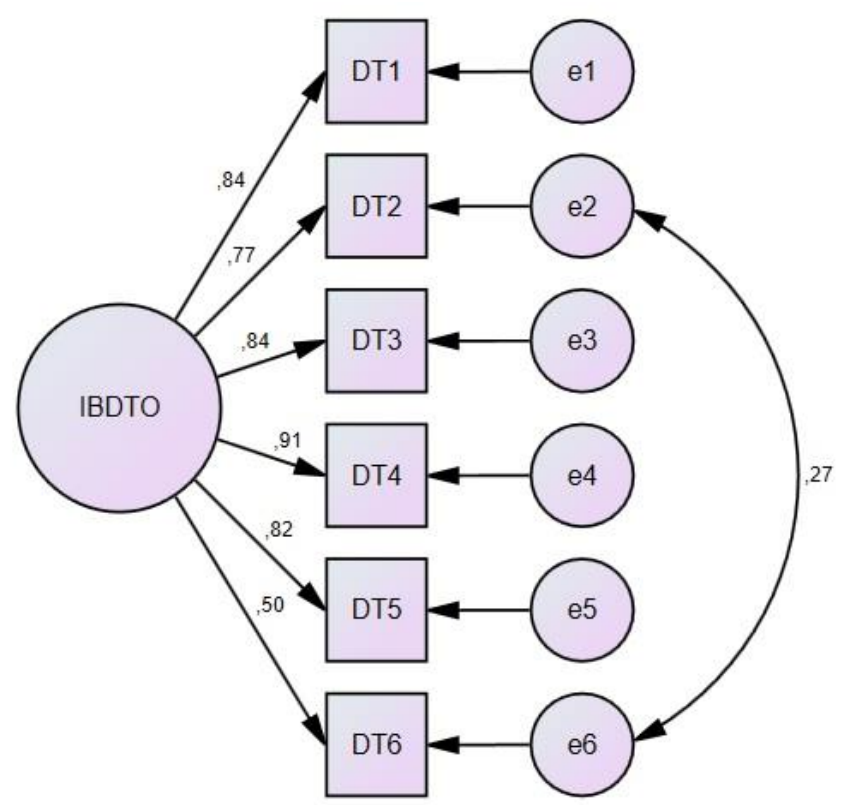

Şekil 1. DFA Sonuçları

Şekil 1'den anlaşılabileceği gibi İşe Bağlı Duygusal Tükenmişlik Ölçeğine ait ifadelerin faktör yükleri .50 ile .91 arasında değişmektedir. Uyum iyiliği değerlerinin kabul edilebilir sınırlar içerisinde yer almasına karşın birbirine yakın 2 (iş gününün sonunda kendimi bitkin hissediyorum) ve 6 (işimde çok çalıştı̆̆ımı hissediyorum) numaralı ifadelerin hata kovaryanslarının bağlanması yoluyla uyum iyiliği değerleri iyi uyum seviyesine getirilmiştir. Bu bağlama neticesinde özellikle $\chi 2 /(\mathrm{df})$ değerinin 4.872'den 2.982'ye ulaşması sağlanmıştır.

\section{Güvenilirlik Analizi}

İşe Bağlı Duygusal Tükenmişlik Ölçeğine dair gerçekleştirilen güvenilirlik analizi neticesinde elde edilen değerler ve ifadelere ait istatistiki bilgiler Tablo 3 'te verilmiştir. 
Çukurova Üniversitesi Sosyal Bilimler Enstitüsü Dergisi, Cilt 30, Sayı 1, 2021, Sayfa 142-149

Tablo 3: İşe Bağlı Duygusal Tükenmişlik Ölçeğine İlişkin Madde Analizi Sonuçları

\begin{tabular}{|c|c|c|c|c|c|c|}
\hline Madde No & Ort. & S.S. & Çarp. & Bask. & $\begin{array}{c}\text { Düzeltilmiş } \\
\text { Madde Toplam } \\
\text { Korelasyonu }\end{array}$ & $\begin{array}{c}\text { Maddelerin } \\
\text { Silinmesi } \\
\text { Durumunda Alfa }\end{array}$ \\
\hline 1 & 2.79 & 1.215 & .234 & -.765 & .789 & .879 \\
\hline 2 & 3.30 & 1.186 & -.219 & -.755 & .763 & .883 \\
\hline 3 & 2.44 & 1.341 & .550 & -.895 & .776 & .880 \\
\hline 4 & 2.64 & 1.391 & .358 & -.987 & .851 & .868 \\
\hline 5 & 2.30 & 1.382 & .714 & -.762 & .756 & .883 \\
\hline 6 & 3.45 & 1.347 & -.409 & -.941 & .505 & .920 \\
\hline
\end{tabular}

Tablo 3 incelendiği zaman ölçeğe dair madde ortalamalarının 2.30 ile 3.45 arasında değişen değerler aldığ görülmektedir. Ölçeğe ait ifadelerin çarpıklık basıklık değerlerinin ise -1 ile +1 arasında değişen değerler alması nedeniyle normal dağılıma uygunluğu ifade edilebilir. İfadelere dair düzeltilmiş madde toplam korelasyonları .505 ile .851 arasında değişmektedir. Nitekim Büyüköztürk (2003)'e göre ölçeğe dair maddelerin ayırt etme seviyesinde olması için .30'dan büyük değerlere sahip olması gerekmektedir. İşe Bağlı Duygusal Tükenmişlik Ölçeğinin Cronbach alfa iç tutarlılık katsayısı .903 olarak tespit edilmiş olup yüksek güvenilirlik seviyesine sahip olduğu ifade edilebilir. Ölçeğe dair maddelerin silinmesi durumunda ise elde edilecek olan değerlerin mevcut katsayıya oldukça yakın olduğu anlaşılmaktadır. Gerçekleştirilen analizler neticesinde ölçeğe dair elde edilen iki yarı güvenilirliğine ait değerlerden madde korelasyonu .839, Spearman-Brown katsayıs1 ise .913 olarak bulunmuştur.

\section{SONUÇ}

Wharton (1993) tarafindan geliştirilen İşe Bağlı Duygusal Tükenmişlik Ölçeğinin (Job-Related Emotional Exhaustion Scale) Türkçe uyarlamasının amaçlandığ 1 bu çalışmada ölçeğin geçerliliği ve güvenilirliği sınanmıştır. Ölçeğin geçerliliğinin sınanması maksadıyla yapılan AFA ve DFA neticesinde ölçeğin orijinalinde olduğu gibi tek boyutlu ve 6 ifadeden oluşan yapısı muhafaza edilmiş ve yalnızca iki madde arasında hata kovaryans bağlamasına başvurulmuştur.

İşe Bağlı Duygusal Tükenmişlik Ölçeğinin güvenilirliğinin sınanması neticesinde Cronbach alfa katsayısının .903 olduğu tespit edilmiş, iki yarı güvenilirliğine ait değerlerden madde korelasyonu .839, Spearman-Brown katsayısı ise .913 olarak bulunmuştur.

Gerçekleştirilen analizler neticesinde elde edilen bulgulardan hareketle İşe Bağlı Duygusal Tükenmişlik Ölçeğinin Türk kültüründe rahatlıkla kullanılabileceğini söylemek mümkündür. Ölçeğe dair ifadelerin yer aldığı Tablo 4 nihai hal olarak kullanıma uygun şekilde verilmiştir.

Tablo 4. İșe Bağlı Duygusal Tükenmișlik Ölçeği Türkçe Uyarlaması İfadeleri

\begin{tabular}{|l|l|}
\hline Madde No & İfadeler \\
\hline 1 & İşimden dolayı duygusal olarak tükenmiş hissediyorum \\
\hline 2 & İş gününün sonunda kendimi bitkin hissediyorum \\
\hline 3 & Sabah kalkmaktan ve iş yerinde yeni bir günle yüzleşmek zorunda olmaktan yıldım \\
\hline 4 & İsimden dolayı psikolojik olarak yıpranmış hissediyorum \\
\hline 5 & İşimden dolayı hayal kırıklığına uğramış hissediyorum \\
\hline 6 & Isşimde çok çalıştığımı hissediyorum \\
\hline
\end{tabular}

Ölçek orijinaline sadık kalınarak 5 'li likert tipinde ve $1=$ iş yerinde asla bu şekilde hissetmiyorum, $5=$ her gün bu şekilde hissediyorum şeklinde dizayn edilmiştir.

\section{KAYNAKLAR}

Aypay, A. (2011). İlköğretim II. kademe öğrencileri için okul tükenmişliği ölçeği: Geçerlik ve güvenirlik çalışması. Kuram ve Uygulamada Eğitim Bilimleri, 11(2), 511-527. 
Çukurova Üniversitesi Sosyal Bilimler Enstitüsü Dergisi, Cilt 30, Sayı 1, 2021, Sayfa 142-149

Bozionelos, N. (2006). Mentoring and expressive network resources: Their relationship with career success and emotional exhaustion among Hellenes employees involved in emotion work. The International Journal of Human Resource Management, 17(2), 362-378.

Brown, CG (2012). A systematic review of the relationship between self-efficacy and burnout in teachers. Educational and Child Psychology, 29(4), 47.

Brown, LA \& Roloff, ME (2011). Extra-role time, burnout, and commitment: The power of promises kept. Business Communication Quarterly, 74(4), 450-474.

Burke, RJ \& Greenglass, ER (2001). Hospital restructuring, work-family conflict and psychological burnout among nursing staff. Psychology \& health, 16(5), 583-594.

Burke, RJ \& Richardson, AM (2000). Psychological burnout in organizations. Handbook of organizational behavior, 2, 327-368.

Büyüköztürk, Ş. (2003). Sosyal bilimler için veri analizi el kitabı. Pegem Akademi Yayıncılık.

Cherniss, C. \& Cherniss, C. (1980). Staff burnout: Job stress in the human services (p. 21). Beverly Hills, CA: Sage publications.

Cole, MS, Bernerth, JB, Walter, F. and Holt, DT (2010). Organizational justice and individuals' withdrawal: Unlocking the influence of emotional exhaustion. Journal of Management Studies, 47(3), 367-390.

Cooper, CL, Cooper, CP, Dewe, PJ, O'Driscoll, MP \& O'Driscoll, MP (2001). Organizational stress: A review and critique of theory, research, and applications. Sage.

Cox, T., Kuk, G. and Leiter, MP (1993). Burnout, health, work stress, and organizational healthiness.

Cropanzano, R., Rupp, DE \& Byrne, ZS (2003). The relationship of emotional exhaustion to work attitudes, job performance, and organizational citizenship behaviors. Journal of Applied psychology, 88(1), 160.

Edwards, JR, Baglioni, AJ \& Cooper, CL (1990). Examining the relationships among self-report measures of the Type A behavior pattern: The effects of dimensionality, measurement error, and differences in underlying constructs. Journal of Applied Psychology, 75(4), 440-454.

Forza, C. \& Filippini, R. (1998). TQM impact on quality conformance and customer satisfaction: a causal model. International journal of production economics, 55(1), 1-20.

Freudenberger, HJ (1986). The issues of staff burnout in therapeutic communities. Journal of psychoactive drugs, 18(3), 247-251.

Garrosa, E., Moreno-Jimenez, B., Liang, Y. \& Gonzalez, JL (2008). The relationship between sociodemographic variables, job stressors, burnout, and hardy personality in nurses: An exploratory study. International journal of nursing studies, 45(3), 418-427.

Ghorpade, J., Lackritz, J. \& Singh, G. (2007). Burnout and personality: Evidence from academia. Journal of career assessment, 15(2), 240-256.

Gkorezis, P., Petridou, E. \& Krouklidou, T. (2015). The detrimental effect of machiavellian leadership on employees' emotional exhaustion: organizational cynicism as a mediator. Europe's journal of psychology, 11(4), 619. 
Çukurova Üniversitesi Sosyal Bilimler Enstitüsü Dergisi, Cilt 30, Sayı 1, 2021, Sayfa 142-149

Halbesleben, JR \& Bowler, WM (2007). Emotional exhaustion and job performance: the mediating role of motivation. Journal of applied psychology, 92(1), 93.

Houkes, I., Janssen, PP, De Jonge, J. \& Bakker, AB (2003). Specific determinants of intrinsic work motivation, emotional exhaustion and turnover intention: A multisample longitudinal study. Journal of Occupational and organizational Psychology, 76(4), 427-450.

Jeon, L., Buettner, CK \& Grant, AA (2018). Early childhood teachers' psychological well-being: Exploring potential predictors of depression, stress, and emotional exhaustion. Early education and development, 29(1), 53-69.

Kelecek, S., Kara, FM, Çetinkalp, FZK \& Aşçı, FH (2016). "Sporcu Tükenmişlik Ölçeği” nin Türkçe uyarlamas1. Spor Bilimleri Dergisi, 27(4), 150-161.

Kline, P. (1994). A general description of factor analysis. An Easy Guide to Factor Analysis.

Lee, RT \& Ashforth, BE (1996). A meta-analytic examination of the correlates of the three dimensions of job burnout. Journal of applied Psychology, 81(2), 123.

Mäkikangas, A. \& Kinnunen, U. (2003). Psychosocial work stressors and well-being: Self-esteem and optimism as moderators in a one-year longitudinal sample. Personality and individual differences, 35(3), 537-557.

Maslach, C. \& Jackson, SE (1984). Burnout in organizational settings. Applied social psychology annual.

Maslach, C., Schaufeli, WB \& Leiter, MP (2001). Job burnout. Annual review of psychology, 52(1), $397-422$.

Moon, TW \& Hur, WM (2011). Emotional intelligence, emotional exhaustion, and job performance. Social Behavior and Personality: an international journal, 39(8), 1087-1096.

Nunnally, JC (1978). Psychometric theory. McGraw-Hill.

Omdahl, BL \& O'Donnell, C. (1999). Emotional contagion, empathic concern and communicative responsiveness as variables affecting nurses' stress and occupational commitment. Journal of Advanced Nursing, 29(6), 1351-1359.

Papathanasiou, IV, Fradelos, EC, Kleisiaris, CF, Tsaras, K., Kalota, MA \& Kourkouta, L. (2014). Motivation, leadership, empowerment and confidence: their relation with nurses' burnout. Materia sociomedica, 26(6), 405.

Salanova, M. \& Llorens, S. (2008). Current state of research on Burnout and future challenges. Papeles del psicólogo, 29(1), 59-67.

Schaible, LM \& Gecas, V. (2010). The impact of emotional labor and value dissonance on burnout among police officers. Police Quarterly, 13(3), 316-341.

Schermuly, CC \& Meyer, B. (2016). Good relationships at work: The effects of Leader-Member Exchange and Team-Member Exchange on psychological empowerment, emotional exhaustion, and depression. Journal of Organizational Behavior, 37(5), 673-691.

Schulz, R., Greenley, JR \& Brown, R. (1995). Organization, management, and client effects on staff burnout. Journal of health and social behavior, 333-345.

Seçer, İ., Halmatoc, S., Veyis, F. \& Bümyamin, ATES (2013). Okul tükenmişlik ölçeğinin Türk kültürüne uyarlanması: güvenirlik ve geçerlik çalışması. Turkish Journal of Education, 2(2), 16-24. 
Çukurova Üniversitesi Sosyal Bilimler Enstitüsü Dergisi, Cilt 30, Sayı 1, 2021, Sayfa 142-149

Shanafelt, TD, Boone, S., Tan, L., Dyrbye, LN, Sotile, W., Satele, D., ... \& Oreskovich, MR (2012). Burnout and satisfaction with work-life balance among US physicians relative to the general US population. Archives of internal medicine, 172(18), 1377-1385.

Shirom, A., Cooper, CL \& Robertson, IT (1989). International review of industrial and organizational psychology.

Skaalvik, EM \& Skaalvik, S. (2016). Teacher stress and teacher self-efficacy as predictors of engagement, emotional exhaustion, and motivation to leave the teaching profession. Creative Education, 7(13), 1785.

Stordeur, S., D'hoore, W. \& Vandenberghe, C. (2001). Leadership, organizational stress, and emotional exhaustion among hospital nursing staff. Journal of advanced nursing, 35(4), 533-542.

Tümkaya, S. (2000). Akademik tükenmişlik ölçeğinin geliştirilmesi. Hacettepe Üniversitesi Eğitim Fakültesi Dergisi, 19(19).

Tümkaya, S., Sabahattin, ÇAM, \& Çavuşoğlu, I. (2009). Tükenmişlik Ölçeği Kısa Versiyonu'nun Türkçe’ye uyarlama, geçerlik ve güvenirlik çalı̧̧ması. Çukurova Üniversitesi Sosyal Bilimler Enstitüsü Dergisi, 18(1), 387-398.

Wang, Y., Liu, L., Wang, J. \& Wang, L. (2012). Work- family conflict and burnout among Chinese doctors: the mediating role of psychological capital. Journal of occupational health, 54(3), 232-240.

West, CP, Dyrbye, LN, Sloan, JA \& Shanafelt, TD (2009). Single item measures of emotional exhaustion and depersonalization are useful for assessing burnout in medical professionals. Journal of general internal medicine, 24(12), 1318.

Wharton, AS (1993). The affective consequences of service work: Managing emotions on the job. Work and occupations, 20(2), 205-232.

Wittmer, JL \& Martin, JE (2010). Emotional exhaustion among employees without social or client contact: The key role of nonstandard work schedules. Journal of Business and Psychology, 25(4), 607-623.

Yeniçeri, Ö., Demirel, Y. \& Seçkin, Z. (2009). Örgütsel adalet ile duygusal tükenmişlik arasındaki ilişki: İmalat sanayi çalışanları üzerine bir araştırma. Karamanoğlu Mehmetbey Üniversitesi Sosyal ve Ekonomik Araştırmalar Dergisi, 2009(1), 83-99. 